\title{
Fabrication of Copper Matrix Composites and Simultaneous Bonding with Aluminum Alloy Using Combustion Reaction of Cu-Ti-B System
}

\author{
Yong-Jai Kwon*, Makoto Kobashi and Naoyuki Kanetake \\ Department of Materials Processing Engineering, Graduate School of Engineering, Nagoya University, Nagoya 464-8603, Japan
}

$\mathrm{TiB}_{2}$ particle reinforced $\mathrm{Cu}$ matrix composites were fabricated by a combustion reaction between Ti and $\mathrm{B}$ in a Cu-Ti-B system. Addition to the fabrication of the composite, its bonding with $1050 \mathrm{Al}$ alloy were successfully carried out in a single-step process by using the high heat of the combustion reaction. When the combustion synthesis of $\mathrm{Cu}-50 \mathrm{vol} \% \mathrm{TiB}_{2}$ was attempted, a minute quantity of unfavorable $\mathrm{Cu}_{3} \mathrm{Ti}$ was formed with $\mathrm{TiB}_{2}$ in the $\mathrm{Cu}$ matrix. However, for $\mathrm{Cu}-60 \mathrm{vol} \% \mathrm{TiB}_{2}$, only fine $\mathrm{TiB}_{2}$ particles below $4 \mu \mathrm{m}$ in diameter were formed in situ, and homogeneously distributed in the $\mathrm{Cu}$ matrix. Also for $\mathrm{Cu}-70$ vol\% $\mathrm{TiB}_{2}$, the combustion reaction occurred completely without forming any unfavorable phases, although some $\mathrm{Cu}$ was evaporated during synthesizing the composite. In a Ti-B binary system, any reaction was not generated in the temperature range from room temperature to $1473 \mathrm{~K}$. However, in the $\mathrm{Cu}$-Ti-B ternary system, the combustion reaction was generated near the melting point of $\mathrm{Cu}$, suggesting that it was activated by molten $\mathrm{Cu}$. Preheating before inducing the combustion reaction was effective in bonding with long $\mathrm{Al}$ rods and also in reducing bonding defects. Intermetallic compounds consisting of $\mathrm{Al}, \mathrm{Cu}$ and $\mathrm{Ti}$ were observed with unreacted $\mathrm{B}$ in the bonded layer. For the bonded specimen with a $\mathrm{Cu}$ insert layer, a eutectic microstructure of $\mathrm{Al}$ and $\mathrm{Cu}$ was formed between the $\mathrm{Al}$ alloy and $\mathrm{Cu}$ insert, and unreacted $\mathrm{B}$ was observed with a compound of $\mathrm{Cu}$ and $\mathrm{Ti}$ between the composite and $\mathrm{Cu}$ insert. The bonding strength was improved by inserting the $\mathrm{Cu}$ layer and by preheating. The bonded specimen with no insert layer was fractured between the composite and the $\mathrm{Al}$ alloy. By inserting the $\mathrm{Cu}$ layer with preheating, the fracture occurred between the $\mathrm{Al}$ alloy and the $\mathrm{Cu}$ insert.

(Received April 15, 2004; Accepted September 13, 2004)

Keywords: combustion reaction, simultaneous bonding, copper matrix composite, titanium diboride, adiabatic temperature, ignition temperature, aluminum alloy, preheating, copper insert, bonding strength

\section{Introduction}

Much attention has been focused on $\mathrm{Cu}$ matrix composites with ceramic reinforcements, because of their excellent combination of thermal and electrical conductivities, microstructural stability and strength retention at elevated temperatures. $^{1-9)}$ Especially, $\mathrm{Cu}$ matrix composites with high volume fractions (more than $50 \mathrm{vol} \%$ ) of the reinforcements have been studied due to their very low coefficient of thermal expansion (CTE). ${ }^{6-9)}$ This feature is very important in thermal management systems in electronic devices, such as heat sinks, packaging for high voltage chips and packaging base plates. In addition, these composites may also be useful in the fields where high wear resistance is also needed, such as valve sheets of automobile engines.

$\mathrm{TiB}_{2}$ particle reinforced $\mathrm{Cu}$ matrix $\left(\mathrm{TiB}_{2} / \mathrm{Cu}\right)$ composites have been considered one of the best candidates for the above-mentioned applications, because the $\mathrm{TiB}_{2}$ addition greatly enhances the mechanical properties, such as stiffness, hardness and wear resistance, and decreases the coefficient of thermal expansion (CTE), while it reduces the electrical and thermal conductivities much less than the addition of most other ceramic reinforcements. ${ }^{6}$ )

On the other hand, much effort has been concentrated on in situ processes including combustion synthesis among various processing techniques for metal matrix composites (MMCs). In these processes, the in situ formed reinforcement is generally fine and thermodynamically stable, and is homogeneously distributed with forming clean and strong inter-

\footnotetext{
*Graduate Student, Nagoya University.

Present address: National Institute of Advanced Industrial Science and Technology (AIST), Nagoya 463-8560, Japan.

Corresponding author, E-mail: yj-kwon@aist.go.jp
}

faces with the matrix. Therefore, in situ processed MMCs exhibit many attractive advantages including excellent mechanical properties. ${ }^{10)}$ Especially, the combustion synthesis provides significant benefits from technical and economic viewpoints, such as (1) the process is relatively simple because there is no need for complex equipments, (2) the high reaction rate offers high productivity, (3) it is an energy-efficient technology because the combustion reaction can be generated by a small amount of energy, and (4) the evaporation of impurities allows production of high purity materials, which results from the fact that the materials are exposed at extremely high temperatures during processing. ${ }^{10-15)}$

In the meanwhile, combustion reactions have also been applied in bonding of various materials. ${ }^{16-22)}$ However, most previous researches have been associated with the fabrication of coatings (less than several hundred microns in thickness) for surface modification of substrate materials or bonding using reactive insert materials. Namely, there is little information concerning simultaneous bonding of large bulk materials by using the high reaction heat generated during synthesizing the materials.

In this context, we have studied the combustion synthesis process not only as a manufacturing technology for large bulk MMCs but also as their simultaneous bonding process. ${ }^{23,24)}$ In the present research, $\mathrm{TiB}_{2} / \mathrm{Cu}$ composites were combustion-synthesized and were simultaneously bonded with aluminum rods. This combination will be applicable to simultaneous bonding between aluminum alloy cylinder heads and valve sheets of automobile engines. The basic principle of the simultaneous bonding process by the combustion reaction in the present research is schematically illustrated in Fig. 1. Namely, (a) an $\mathrm{Al}$ rod is set on a compacted reactant, which is composed of $\mathrm{Cu}$, Ti and $\mathrm{B}$ 


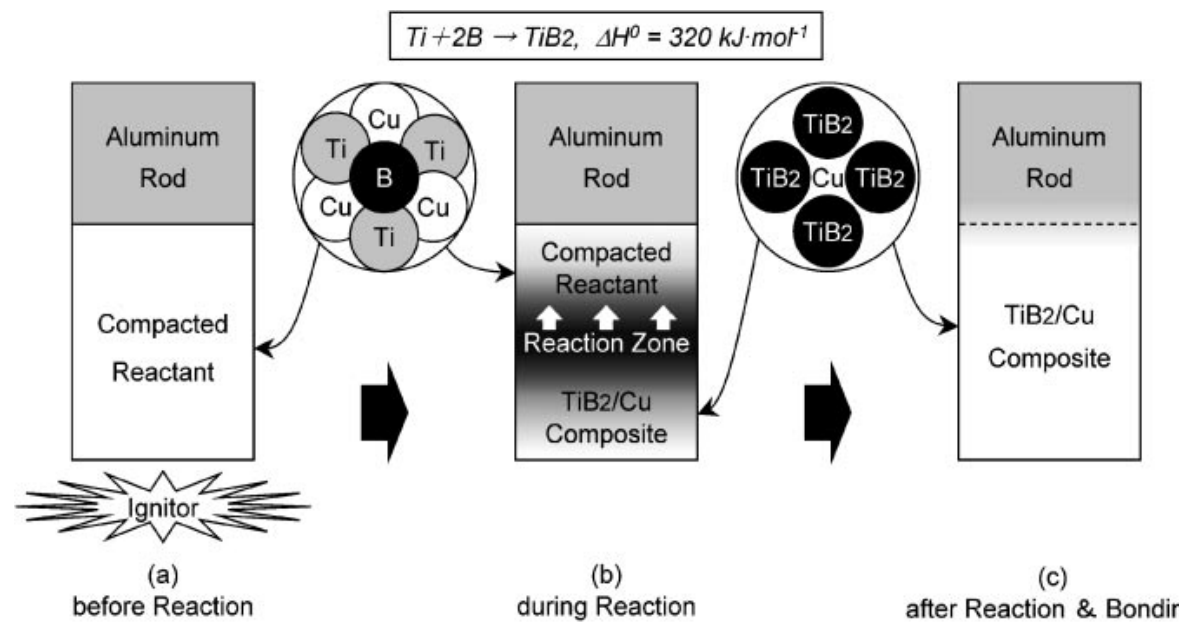

Fig. 1 Schematic representation of the basic principle of the simultaneous bonding process between the $\mathrm{TiB}_{2} / \mathrm{Cu}$ composite and the aluminum alloy by the combustion reaction in the $\mathrm{Cu}$-Ti-B system.

powders, and then the bottom surface of the reactant is heated by an ignitor. (b) The combustion reaction between $\mathrm{Ti}$ and $\mathrm{B}$ occurs at the bottom, with generating the high reaction heat, as described by a chemical formula. ${ }^{25)}$ As a result, $\mathrm{TiB}_{2}$ particles are formed in situ as the reinforcement phase in a $\mathrm{Cu}$ matrix. Shortly afterwards, the reaction self-propagates throughout the whole reactant, with converting it into the $\mathrm{TiB}_{2} / \mathrm{Cu}$ composite. And then, (c) the excessive heat of combustion reaction produces a bonded layer between the composite and the Al rod. In this method, two kinds of processes, i.e. the fabrication process of a metal matrix composite and the bonding process of the composite with a metallic material, are simultaneously carried out in a single process by using only the high reaction heat generated during synthesizing the composite. This means that no additional heating is needed for the bonding between them. Therefore, it is believed that this process leads to reduction in production costs through process simplification and energy-saving benefits.

N. Sata investigated in detail the combustion reaction behavior in the Cu-Ti-B System. ${ }^{5)}$ However, in spite of the same reaction system, combustion reaction behavior can be easily changed by various parameters, such as characteristics of starting materials, porosity of compacted reactant, heating method. ${ }^{26-28)}$ Therefore, in the present research, combustion synthesis experiments for the $\mathrm{Cu}-\mathrm{Ti}-\mathrm{B}$ system were first carried out to determine optimum conditions for the simultaneous bonding between the combustion synthesized $\mathrm{TiB}_{2} / \mathrm{Cu}$ composite and $1050 \mathrm{Al}$ alloy. And then, the influence of preheating, length of $\mathrm{Al}$ rod and insert metal on the microstructure and strength of the bonded specimens was experimentally investigated.

\section{Experimental Procedure}

$\mathrm{Cu}$ (particle size: $<177 \mu \mathrm{m}$, purity: 99.9\%), Ti (particle size: $<44 \mu \mathrm{m}$, purity: $99.9 \%$ ), and B (particle size: $<44 \mu \mathrm{m}$, purity: $99 \%$ ) powders were used as starting materials. It was assumed that all the $\mathrm{Ti}$ and $\mathrm{B}$ powders turn into $\mathrm{TiB}_{2}$ particles with the mole ratio of $\mathrm{Ti}: \mathrm{B}=1: 2$ by the combustion reaction. And then, the starting material powders were mixed in each ratio in order to produce $\mathrm{Cu}$ matrix composites including 50, 60 and $70 \mathrm{vol}_{\%} \mathrm{TiB}_{2}$ particles, respectively. In the present research, these specimens were denoted as $\mathrm{Cu}-50$, 60 and $70 \mathrm{vol} \% \mathrm{TiB}_{2}$, respectively. The powder mixtures were compacted into a cylindrical shape by a pressure of $200 \mathrm{MPa}$. The diameter and height of the compacted reactants were $15 \mathrm{~mm}$ and $20 \mathrm{~mm}$, respectively. A compacted powder mixture of $\mathrm{Ti}$ and $\mathrm{B}_{4} \mathrm{C}$ was also used as an ignitor to generate the combustion reaction, due to its high exothermicity $\left(3 \mathrm{Ti}+\mathrm{B}_{4} \mathrm{C} \rightarrow 2 \mathrm{TiB}_{2}+\mathrm{TiC}, \Delta H^{0}=761 \mathrm{~kJ}\right){ }^{25,29)}$ Commercially pure $1050 \mathrm{Al}$ alloy rods with a diameter of $15 \mathrm{~mm}$ and a length of 20 to $60 \mathrm{~mm}$ were used for simultaneous bonding with the combustion synthesized $\mathrm{TiB}_{2} / \mathrm{Cu}$ composite.

The combustion synthesis and simultaneous bonding experiments were carried out under an argon gas atmosphere. For the bonding experiments, a pressure of $0.05 \mathrm{MPa}$ was applied to the $\mathrm{Al}$ rod from the top. To investigate the influence of preheating before generating the combustion reaction on the microstructure and strength of the bonded specimens, the bonding experiments were carried out at room temperature or after preheating at $433 \mathrm{~K}$.

After the experiments, the phases and microstructures were characterized using X-ray diffraction (XRD), scanning electron microscopy (SEM) and energy dispersive spectroscopy (EDS). In addition, an ignition temperature at which the combustion reaction starts was investigated by differential thermal analysis (DTA). It was carried out under an argon gas atmosphere in the temperature range from room temperature to $1473 \mathrm{~K}$ at a heating rate of $50 \mathrm{~K} \cdot \mathrm{min}^{-1}$. To examine the bonding strength, tensile tests were also performed at room temperature with a crosshead speed of $1 \mathrm{~mm} \cdot \mathrm{min}^{-1}$.

\section{Results and Discussion}

\subsection{Combustion synthesis of $\mathrm{TiB}_{2} / \mathrm{Cu}$ composites}

Figure 2 shows XRD patterns of (a) $\mathrm{Cu}-50$ vol\% $\mathrm{TiB}_{2}$, (b) $\mathrm{Cu}-60$ vol\% $\mathrm{TiB}_{2}$ and (c) $\mathrm{Cu}-70$ vol\% $\mathrm{TiB}_{2}$, which were 


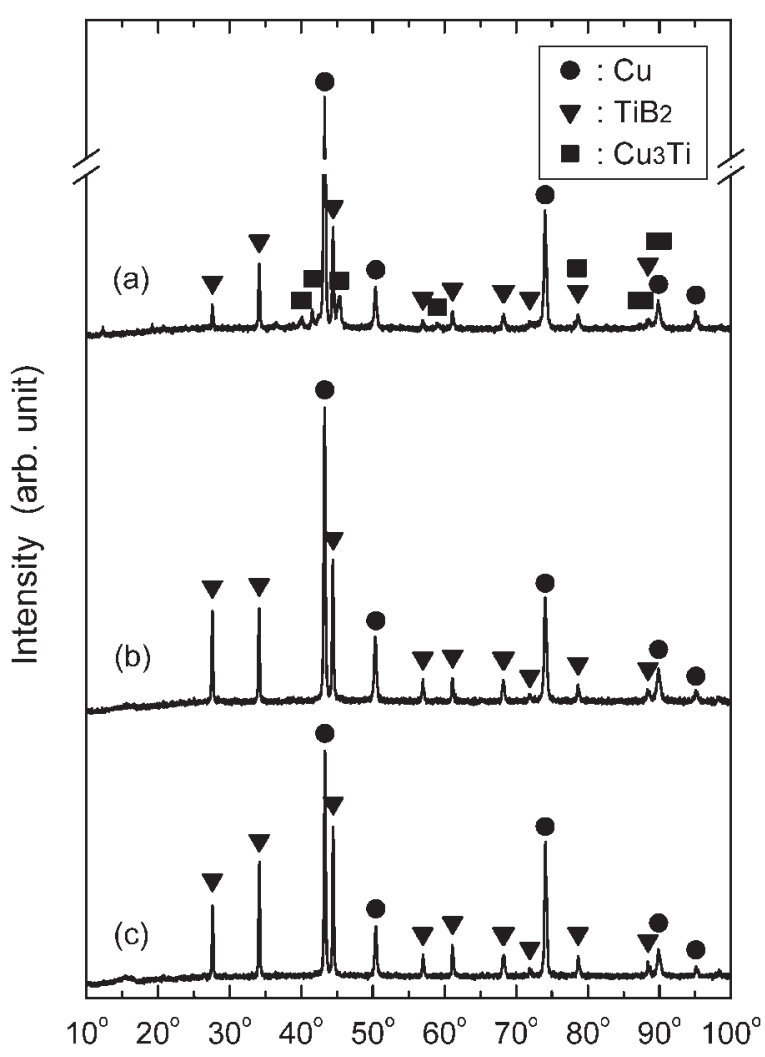

$2 \theta$

Fig. 2 XRD patterns of (a) $\mathrm{Cu}-50$ vol\% $\mathrm{TiB}_{2}$, (b) $\mathrm{Cu}-60$ vol\% $\mathrm{TiB}_{2}$ and (c) $\mathrm{Cu}-70 \mathrm{vol} \% \mathrm{TiB}_{2}$, which were ignited without preheating.

ignited without preheating. For the $\mathrm{Cu}-50$ vol\% $\mathrm{TiB}_{2}$ composition (Fig. 2(a)), a minute quantity of $\mathrm{Cu}_{3} \mathrm{Ti}$, which was unfavorable phase, was detected with $\mathrm{Cu}$ and $\mathrm{TiB}_{2}$. In contrast, for the $\mathrm{Cu}-60$ vol\% $\mathrm{TiB}_{2}$ (Fig. 2(b)) and $\mathrm{Cu}$ 70 vol\% $^{2} \mathrm{TiB}_{2}$ (Fig. 2(c)) compositions, only $\mathrm{Cu}$ and $\mathrm{TiB}_{2}$ were detected without any unfavorable phases. This result confirms that, in these compositions, the combustion reaction propagated throughout the whole reactants with completely converting them into the $\mathrm{TiB}_{2} / \mathrm{Cu}$ composites. However, for the $\mathrm{Cu}-70$ vol\% $\mathrm{TiB}_{2}$ (Fig. 2(c)), some copper-colored fume was observed during the combustion reaction, which was spewed from the specimen. Although not quantified, this means that some $\mathrm{Cu}$ was evaporated because the combustion temperature reached the boiling point of $\mathrm{Cu}\left(2843 \mathrm{~K}^{30}\right)$.

An adiabatic temperature $\left(T_{a d}\right)$ was calculated in each composition in order to investigate a cause of these phenomena associated with the chemical composition. The result is shown in Fig. 3. This temperature is the theoretical maximum temperature calculated by equating the reaction enthalpy to the integrated heat capacity, taking into account any heats of fusion or evaporation and assuming that the combustion reaction occurs under the adiabatic condition. In most combustion reactions, the actual combustion temperature will be lower than the calculated adiabatic temperature, since heat loss is inevitable. However, the adiabatic temperature can be used as the estimated temperature at the front of a propagating combustion reaction. ${ }^{11)}$ Therefore, it is believed that, for the $\mathrm{Cu}-50 \mathrm{vol} \% \mathrm{TiB}_{2}$ composition (Fig. 2(a)), the low combustion temperature, i.e. the low

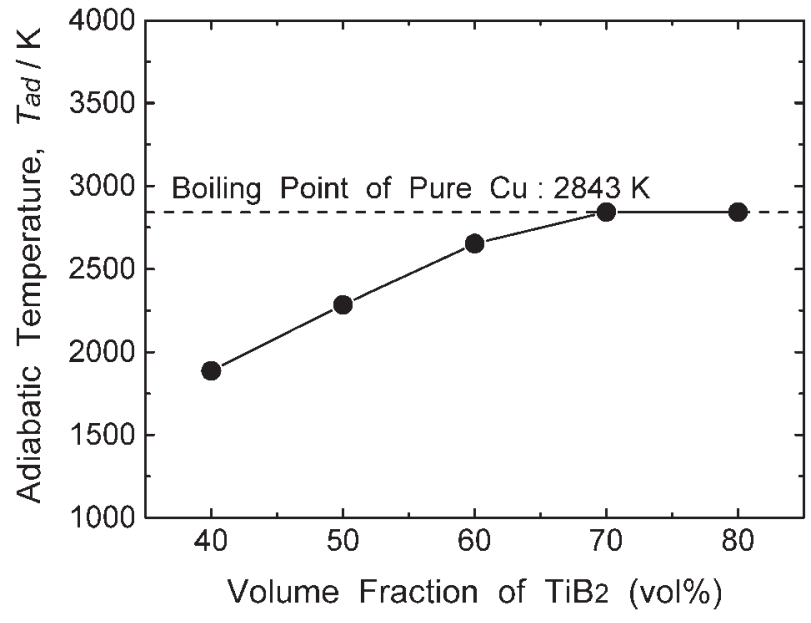

Fig. 3 Relationship between the adiabatic temperature $\left(T_{a d}\right)$ and the volume fraction $\left(V_{f}\right)$ of the combustion synthesized $\mathrm{TiB}_{2}$ in the $\mathrm{Cu}-\mathrm{Ti}-\mathrm{B}$ system.

reaction heat, which resulted from the small volume fraction of combustion synthesized $\mathrm{TiB}_{2}$, is one of the causes of the formation of $\mathrm{Cu}_{3} \mathrm{Ti}$. On the other hand, for the $\mathrm{Cu}$ $60 \mathrm{vol}^{2} \mathrm{TiB}_{2}$ (Fig. 2(b)) and $\mathrm{Cu}-70$ vol\% $\mathrm{TiB}_{2}$ (Fig. 2(c)) compositions, the combustion temperature increases with the volume fraction of $\mathrm{TiB}_{2}$. In consequence, the complete combustion reaction would be generated between Ti and B without forming any unfavorable phases. These results suggest that the about $60 \%$ volume fraction of $\mathrm{TiB}_{2}$ is required for the complete combustion reaction to occur without preheating before generating the combustion reaction in the $\mathrm{Cu}-\mathrm{Ti}-\mathrm{B}$ system. In addition, the adiabatic temperature reaches the boiling point of $\mathrm{Cu}\left(2843 \mathrm{~K}^{30)}\right)$, when the volume fraction of $\mathrm{TiB}_{2}$ is higher than $70 \%$. Therefore, for the $\mathrm{Cu}-70 \mathrm{vol} \% \mathrm{TiB}_{2}$, the evaporation of some $\mathrm{Cu}$ is also one of experimental evidences that the adiabatic temperature is nearly equal to the actual combustion temperature.

Figure 4 shows an SEM micrograph of the combustion

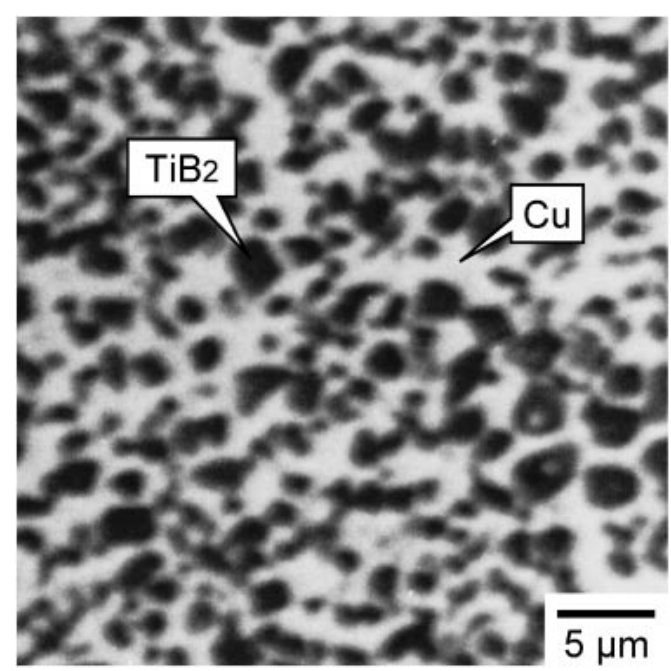

Fig. 4 SEM micrograph of the combustion synthesized $\mathrm{Cu}-60 \mathrm{vol} \% \mathrm{TiB}_{2}$ composite. 


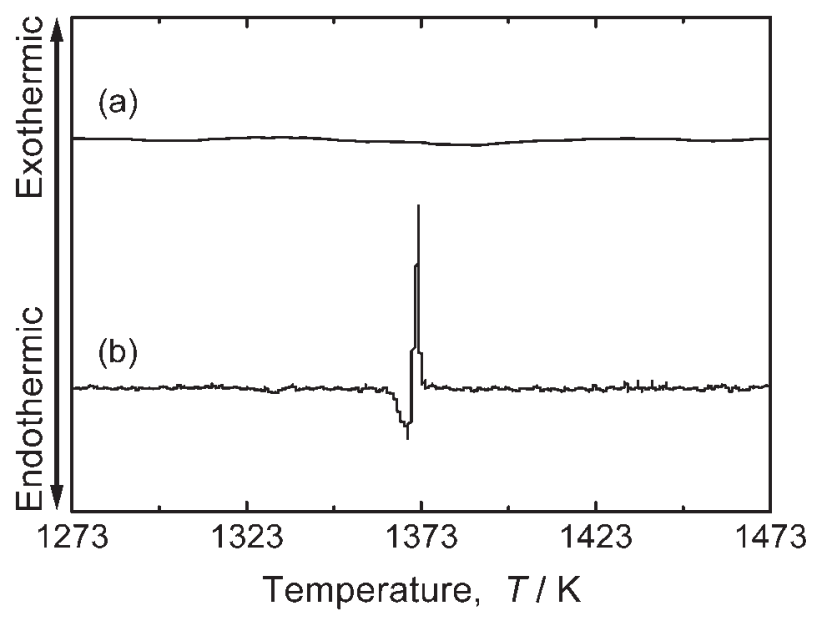

Fig. 5 DTA curves of the compacted reactants with the mole ratios of (a) $\mathrm{Ti}: \mathrm{B}=1: 2$ and (b) $\mathrm{Cu}: \mathrm{Ti}: \mathrm{B}=1.5: 1: 2$.

synthesized $\mathrm{Cu}-60$ vol $\% \mathrm{TiB}_{2}$ composite. It was revealed from the XRD (Fig. 2(b)) and EDS results that the darker part is the $\mathrm{TiB}_{2}$ particles and the brighter part is the $\mathrm{Cu}$ matrix. Only the fine $\mathrm{TiB}_{2}$ particles less than $4 \mu \mathrm{m}$ in diameter were formed in situ by the combustion reaction, and were homogeneously distributed in the $\mathrm{Cu}$ matrix. Any unfavorable phases were not observed in the composite, coinciding with the XRD result (Fig. 2(b)). For a Cu-Ti-C system, ${ }^{27)}$ a relatively large amount of unreacted $\mathrm{C}$ remained in combustion synthesized $\mathrm{TiC} / \mathrm{Cu}$ composites, independently of the chemical composition, when it was assumed that all Ti and $\mathrm{C}$ turn into $\mathrm{TiC}$ with the stoichiometric composition by the combustion reaction. However, in the $\mathrm{Cu}$-Ti-B system, no unreacted $\mathrm{B}$ remained in the combustion synthesized $\mathrm{TiB}_{2} /$ $\mathrm{Cu}$ composites with the relatively high volume fractions of $\mathrm{TiB}_{2}$. This would be because $\mathrm{TiB}_{2}$ has a very narrow solid solution range of 65.6 to 66.7 at $\% \mathrm{~B}$, as described by the Ti-B binary phase diagram. ${ }^{31)}$

Figure 5 shows DTA curves of the compacted reactants with the mole ratios of (a) Ti:B = 1:2 and (b) $\mathrm{Cu}: \mathrm{Ti}: \mathrm{B}=$ 1.5:1:2. For Ti:B = 1:2 (Fig. 5(a)), neither an endothermic nor an exothermic reaction was detected in the temperature range of room temperature to $1473 \mathrm{~K}$. Namely, the combustion reaction between $\mathrm{Ti}$ and $\mathrm{B}$ was not generated. This result confirms that, in the Ti-B binary system, the ignition temperature at which the combustion reaction starts is higher than $1473 \mathrm{~K}$. On the other hand, for $\mathrm{Cu}: \mathrm{Ti}: \mathrm{B}=1.5: 1: 2$ (Fig. 5(b)), which is the same composition as the $\mathrm{Cu}$ $60 \mathrm{vol} \% \mathrm{TiB}_{2}$, a strong exothermic reaction was observed immediately after an endothermic reaction near the melting point of $\mathrm{Cu}(1358 \mathrm{~K}){ }^{30)}$ This result suggests that, after $\mathrm{Cu}$ was melted in first by heating, the exothermic reaction between Ti and B was immediately generated. Therefore, it is believed that, in the $\mathrm{Cu}$-Ti-B ternary system, the combustion reaction is activated by molten $\mathrm{Cu}$ and its ignition temperature is also decreased.

\subsection{Simultaneous bonding}

As mentioned above, only for the $\mathrm{Cu}-60 \mathrm{vol} \% \mathrm{TiB}_{2}$ composition, the $\mathrm{TiB}_{2} / \mathrm{Cu}$ composite was fabricated without both the formation of unfavorable phases and the evaporation

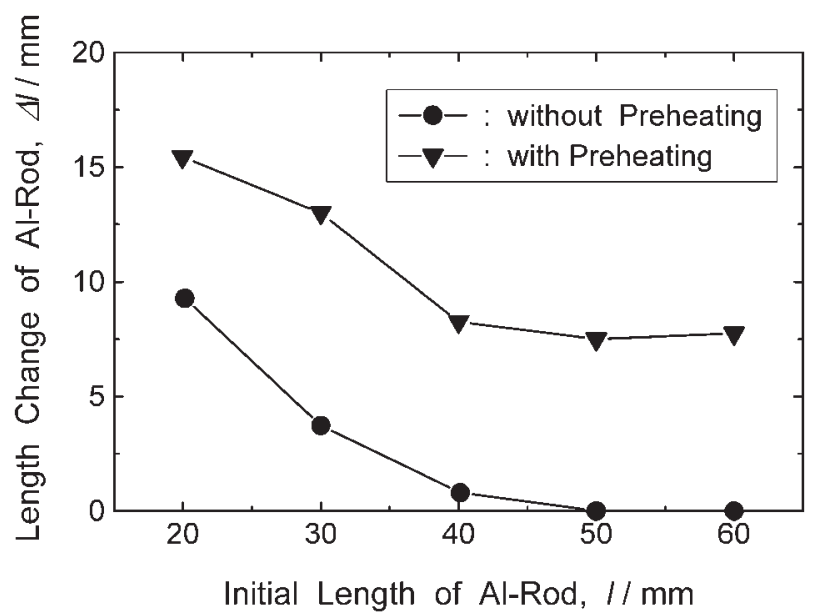

Fig. 6 Length change of the $1050 \mathrm{Al}$ alloy rod by the simultaneous bonding with the combustion synthesized $\mathrm{Cu}-60$ vol\% $\mathrm{TiB}_{2}$ composite.

of $\mathrm{Cu}$ in the present research. Therefore, this composition was selected for simultaneous bonding with $1050 \mathrm{Al}$ alloy rods. In the case without preheating before generating the combustion reaction, the composite was bonded only with the Al rods with lengths of 20 to $40 \mathrm{~mm}$ except for 50 and $60 \mathrm{~mm}$. However, preheating at $433 \mathrm{~K}$ allowed the composite to be successfully bonded also with the Al rods of 50 and $60 \mathrm{~mm}$. Therefore, it is believed that the preheating treatment is highly effective in the simultaneous bonding of relatively long Al rods. Figure 6 shows the length change of the 1050 $\mathrm{Al}$ alloy rods by the simultaneous bonding with the combustion synthesized $\mathrm{Cu}-60 \mathrm{vol} \% \mathrm{TiB}_{2}$ composite. The length change was almost attributable to the melting of $\mathrm{Al}$ rods by the high reaction heat generated during synthesizing the composite. Therefore, it is possible to characterize this length change as the amount of molten $\mathrm{Al}$ alloy. In both cases with and without preheating, the length change exhibited the same tendency. Namely, the severity of length change decreased with increasing the length of $\mathrm{Al}$ rod, and then became almost constant. This result suggests that thermal loss at the bonded interface increases with the length of Al rod but its limit exits. In addition, the length change was larger in the case with preheating than without preheating. This is because the combustion temperature increased with increase in the initial temperature resulting from preheating. Moreover, in the case without preheating, there was almost no length change for the $\mathrm{Al}$ rods of 50 and $60 \mathrm{~mm}$. This result means that, the localized melting of the $\mathrm{Al}$ rod is required for the simultaneous bonding in this system.

Figure 7 shows SEM micrographs of the simultaneously bonded specimens between the $1050 \mathrm{Al}$ alloy rod with the length of $30 \mathrm{~mm}$ and the combustion synthesized $\mathrm{Cu}-$ $60 \mathrm{vol} \% \mathrm{TiB}_{2}$ composite, which were ignited (a) without preheating and (b) after preheating at $433 \mathrm{~K}$, respectively. In the case without preheating (Fig. 7(a)), a lot of defects, such as pores and unbonded regions, were observed in the bonded layer. However, the microstructure was improved by preheating at $433 \mathrm{~K}$ (Fig. 3(b)). This result reveals that the preheating treatment is an important parameter, which affects not only the length of bondable $\mathrm{Al}$ rods but also the microstructure of bonded specimens. Figure 8(1), (2) and (3) show magnified SEM micrographs of the bonded layers on (1) 

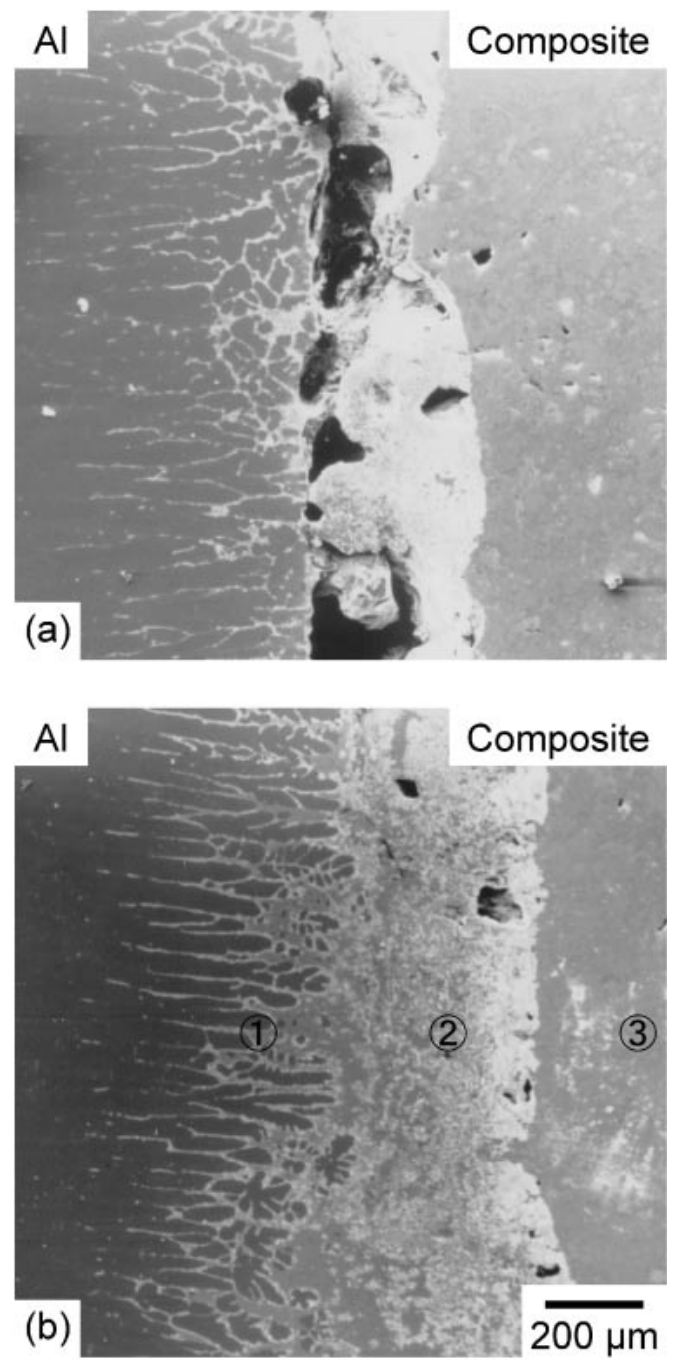

Fig. 7 SEM micrographs of the simultaneously bonded specimens between the $1050 \mathrm{Al}$ alloy rod with the length of $30 \mathrm{~mm}$ and the combustion synthesized $\mathrm{Cu}-60$ vol\% $\mathrm{TiB}_{2}$ composite, which were ignited (a) without preheating and (b) after preheating at $433 \mathrm{~K}$, respectively.

the $\mathrm{Al}$ rod side and (2) the composite side with (3) the composite zone near the bonded interface in Fig. 7(b). On the Al rod side (Fig. 8(1), a eutectic microstructure was formed, which contained an intermetallic compound $\mathrm{CuAl}_{2}$ formed by a eutectic reaction between $\mathrm{Al}$ and $\mathrm{Cu}^{31}$ ) $\mathrm{On}$ the composite side (Fig. 8(2), compounds consisting of $\mathrm{Al}, \mathrm{Cu}$ and $\mathrm{Ti}$ were observed with unreacted $\mathrm{B}$ particles. These microstructure observations indicate that the bonding is mainly realized by the reaction between $\mathrm{Cu}$ and $\mathrm{Al}$. On the other hand, in the composite zone near the bonded interface (Fig. 8(3), $\mathrm{TiB}_{2}$ particles smaller than those in Fig. 4 were formed in the $\mathrm{Cu}$ matrix. It is believed that, near the bonded interface, the growth of $\mathrm{TiB}_{2}$ particles was inhibited by the release of the heat of combustion reaction through the Al rod.

Pure $\mathrm{Cu}$ powders ( $3 \mathrm{~g}$ in weight) were laid on top of the powder mixture for the combustion synthesis of the $\mathrm{Cu}$ $60 \mathrm{vol} \% \mathrm{TiB}_{2}$ composite. And then, these powders were compacted together. As schematically illustrated in Fig. 9(a), this compacted reactant was composed of two layers, i.e. the upper pure $\mathrm{Cu}$ layer and the lower powder mixture layer. Therefore, this reactant turns into a compositionally graded
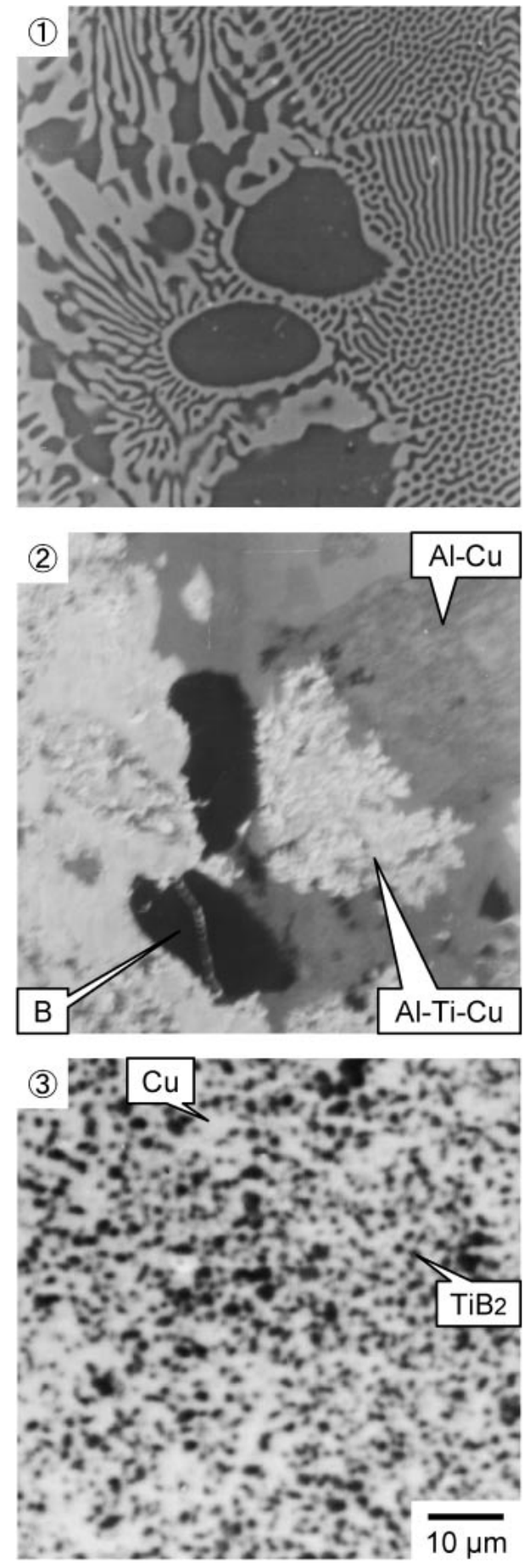

Fig. 8 Magnified SEM micrographs of (1), (2) and (3) zones in Fig. 7(b), respectively.

$\mathrm{TiB}_{2} / \mathrm{Cu}$ composite by the combustion reaction. The $\mathrm{Cu}$ layer acts also as an insert metal to supply enough $\mathrm{Cu}$ required for the bonding between the $\mathrm{TiB}_{2} / \mathrm{Cu}$ composite and the $\mathrm{Al}$ rod. Namely, this compacted reactant was used in order to investigate not only the influence of $\mathrm{Cu}$ insert on the bonding but also the possibility of a simultaneous bonding between a compositionally graded composite and a metallic material by the combustion reaction.

Figures 9(b) and (c) show SEM micrographs of the simultaneously bonded specimen between the $1050 \mathrm{Al}$ alloy rod with the length of $30 \mathrm{~mm}$ and the combustion synthesized 


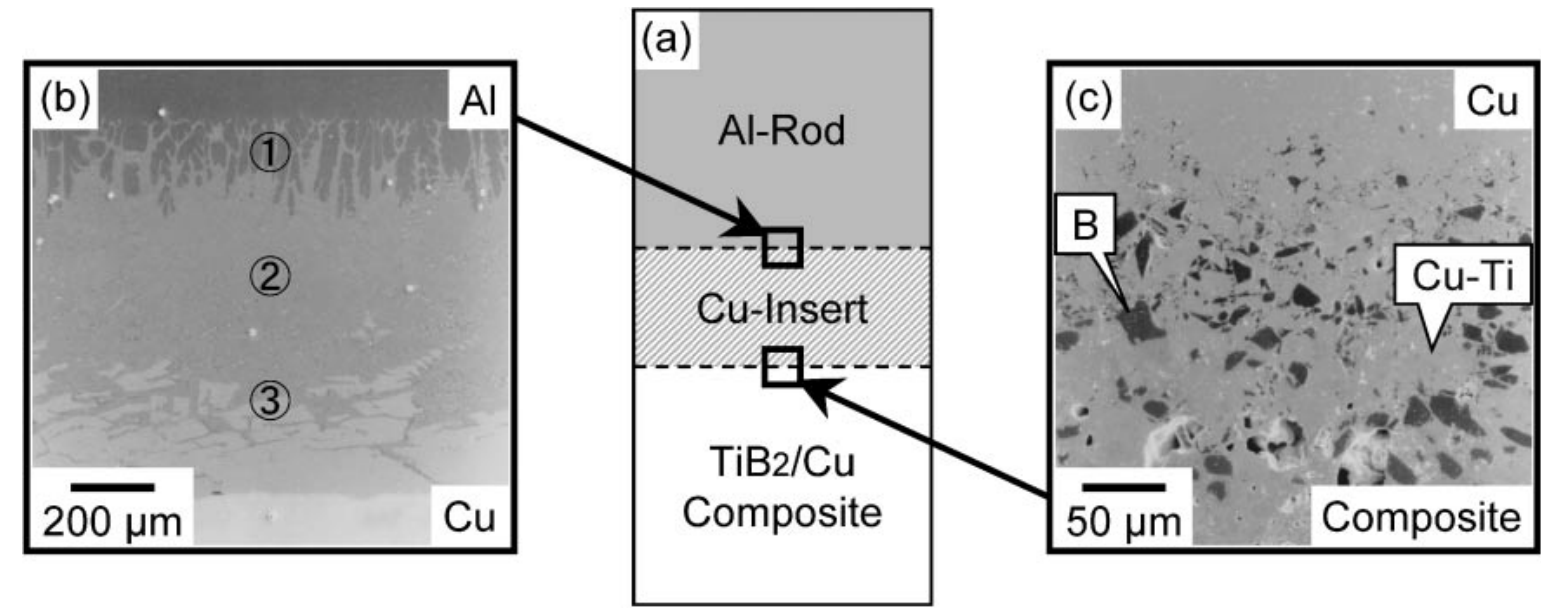

Fig. 9 (a) Schematic illustration of the simultaneous bonding with the pure $\mathrm{Cu}$ insert and SEM micrographs of the bonded layers (b) between the $\mathrm{Al}$ rod and the $\mathrm{Cu}$ insert and (c) between the $\mathrm{Cu}$ insert and the composite of the bonded specimen between the $1050 \mathrm{Al}$ alloy rod with the length of $30 \mathrm{~mm}$ and the combustion synthesized $\mathrm{Cu}-60 \mathrm{vol} \% \mathrm{TiB}_{2}$ composite with the pure $\mathrm{Cu}$ insert layer, which was ignited after preheating at $433 \mathrm{~K}$.

$\mathrm{Cu}-60$ vol\% $\mathrm{TiB}_{2}$ composite with the pure $\mathrm{Cu}$ insert layer, which was ignited after preheating at $433 \mathrm{~K}$. A wide reaction layer was formed between the $\mathrm{Al}$ rod and the $\mathrm{Cu}$ insert, of which the thickness was about $900 \mu \mathrm{m}$ (Fig. 9(b)). Magnified SEM micrographs of (1), (2) and (3) zones in Fig. 9(b) are shown in Fig. 1011, (2) and (3), respectively. These microstructures show that the same eutectic microstructure as Fig. 81 was formed between the $\mathrm{Al}$ rod and the $\mathrm{Cu}$ insert. Therefore, it is apparent that the bonding in this layer was mainly attained by the eutectic reaction between $\mathrm{Al}$ and $\mathrm{Cu}$. On the other hand, between the $\mathrm{Cu}$ insert and the composite (Fig. 9(c)), unreacted B particles were observed with a compound consisting of $\mathrm{Cu}$ and $\mathrm{Ti}$.

Figure 11 shows the bonding strength between the $1050 \mathrm{Al}$ alloy rod and the combustion synthesized $\mathrm{Cu}-60$ vol\% $\mathrm{TiB}_{2}$ composite. Although, in the case without preheating, the bonding strength exhibited about $2 \mathrm{MPa}$, it was enhanced to about $10 \mathrm{MPa}$ by preheating at $433 \mathrm{~K}$. However, in both cases, the bonding strength was hardly dependent on the length of $\mathrm{Al}$ rods. The maximum bonding strength of about $19 \mathrm{MPa}$ was obtained by inserting the pure $\mathrm{Cu}$ layer with preheating at $433 \mathrm{~K}$. Although the bonding strength is still low, this result means that inserting the $\mathrm{Cu}$ layer and preheating is effective in the simultaneous bonding between them.

XRD and microstructural observations were carried out for the fracture surfaces of the simultaneously bonded specimen between the $1050 \mathrm{Al}$ alloy rod with the length of $30 \mathrm{~mm}$ and the combustion synthesized $\mathrm{Cu}-60 \mathrm{vol} \% \mathrm{TiB}_{2}$ composite without the pure $\mathrm{Cu}$ insert layer, which was ignited after preheating at $433 \mathrm{~K}$. Figure 12 shows the XRD patterns of the fracture surfaces on (a) the Al rod side and (b) the composite side. On both sides, the same phases, i.e. $\mathrm{Cu}, \mathrm{TiB}_{2}, \mathrm{CuAl}_{2}$ and $\mathrm{Cu}_{3} \mathrm{Ti}$, were detected, suggesting that the bonded specimen was fractured near the bonded interface between the composite and the Al alloy. Figure 13 shows an SEM micrograph of the fracture surface. Unreacted B particles were observed on the fracture surface, although they were not detected in the XRD results (Fig. 12). After the simultaneous bonding, this unreacted B remains near the bonded interface, as shown in Fig. 8(2). Therefore, it is clear that the fracture occurred near the bonded interface.

Figure 14 shows XRD patterns of the fracture surfaces of the simultaneously bonded specimen between the $1050 \mathrm{Al}$ alloy rod with the length of $30 \mathrm{~mm}$ and the combustion synthesized $\mathrm{Cu}-60$ vol\% $\mathrm{TiB}_{2}$ composite with the pure $\mathrm{Cu}$ insert layer, which was ignited after preheating at $433 \mathrm{~K}$. On both sides, i.e. (a) the Al rod side and (b) the composite side, only $\mathrm{Al}$ and $\mathrm{CuAl}_{2}$ were detected. Figure 15 shows an SEM micrograph of the fracture surface. Only a eutectic microstructure, which consists of $\mathrm{Al}$ and $\mathrm{CuAl}_{2}$, was observed, coinciding with the XRD results (Fig. 14). This eutectic microstructure is formed near the bonded interface between the $\mathrm{Al}$ rod and the $\mathrm{Cu}$ insert by the simultaneous bonding, as shown in Fig. 9(b) and Fig. 10. Therefore, these results confirm that the bonded specimen was fractured near the bonded interface between the $\mathrm{Al}$ rod and the $\mathrm{Cu}$ insert.

In previous researches, ${ }^{32,33)}$ the microstructure and bonding strength between $\mathrm{Al}$ and $\mathrm{Cu}$ were investigated in detail. A variety of intermetallic compounds, such as $\mathrm{CuAl}_{2}, \mathrm{Cu}_{3} \mathrm{Al}$, $\mathrm{Cu}_{4} \mathrm{Al}_{3}, \mathrm{Cu}_{9} \mathrm{Al}_{4}$ and $\mathrm{CuAl}$, were formed in the bonded layer. The bonding strength decreased with increasing the thickness of the brittle intermetallic layer. Enjo et al. $^{32)}$ reported that the bonding strength was very low (about $23 \mathrm{MPa}$ ) in spite of the formation of the thin intermetallic layer with a thickness of 15 to $20 \mu \mathrm{m}$. In addition, the fracture occurred in the brittle intermetallic layer. These results exhibit that the formation of the thick intermetallic compound layer resulted in the low bonding strength between $\mathrm{Al}$ and $\mathrm{Cu}$. In the present research, the thickness of the reaction layer between the $\mathrm{Al}$ rod and the $\mathrm{Cu}$ insert was about $900 \mu \mathrm{m}$. Furthermore, the reaction layer would contain many other intermetallic compounds as well as $\mathrm{CuAl}_{2}$, as predicted from the $\mathrm{Al}-\mathrm{Cu}$ binary phase diagram. ${ }^{31)}$ Therefore, it is believed that, despite inserting the $\mathrm{Cu}$ layer with preheating, the bonding strength resulted in the lower value than $20 \mathrm{MPa}$. 

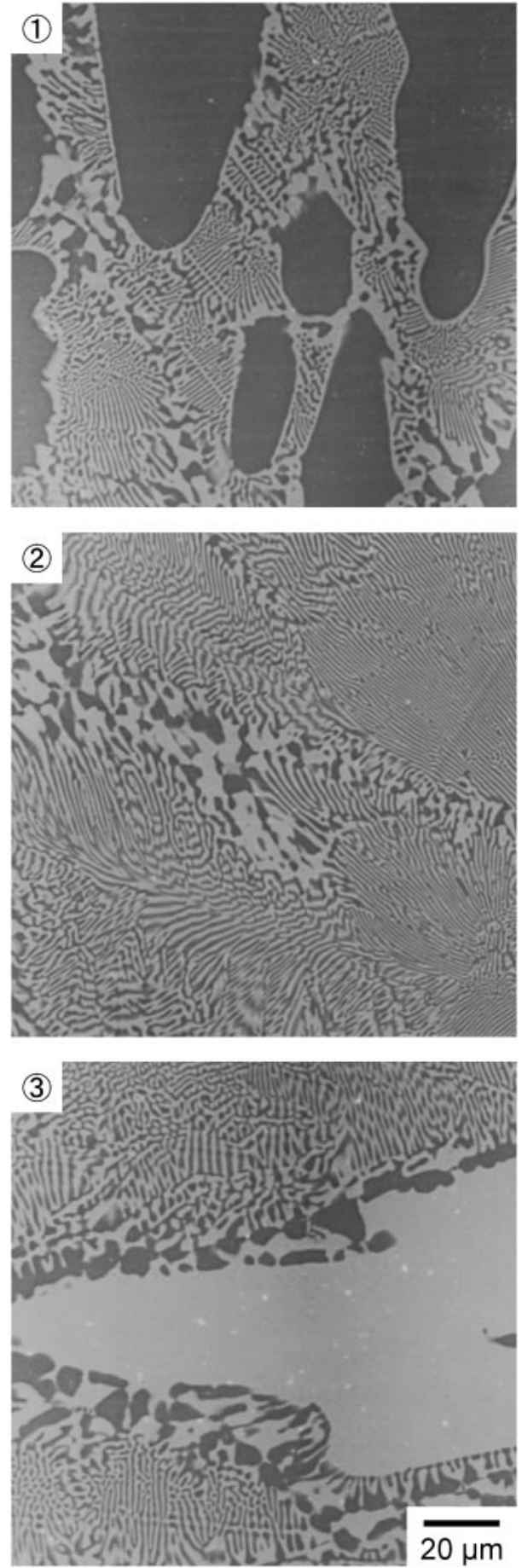

Fig. 10 Magnified SEM micrographs of (1), (2) and (3) zones in Fig. 9(a), respectively.

\section{Conclusions}

The $\mathrm{TiB}_{2}$ particle reinforced $\mathrm{Cu}$ matrix composites were fabricated by the combustion reaction between $\mathrm{Ti}$ and $\mathrm{B}$ in the $\mathrm{Cu}$-Ti-B system. Furthermore, the simultaneous bonding between the composite and $1050 \mathrm{Al}$ alloy was also attempted by using the high heat generated during the combustion reaction. The following results were obtained:

(1) For the $\mathrm{Cu}-50$ vol\% $\mathrm{TiB}_{2}$ composition, a minute quantity of unfavorable $\mathrm{Cu}_{3} \mathrm{Ti}$ was formed with $\mathrm{TiB}_{2}$ in the $\mathrm{Cu}$ matrix. In contrast, for the $\mathrm{Cu}-60$ vol\% $\mathrm{TiB}_{2}$, only fine $\mathrm{TiB}_{2}$ particles

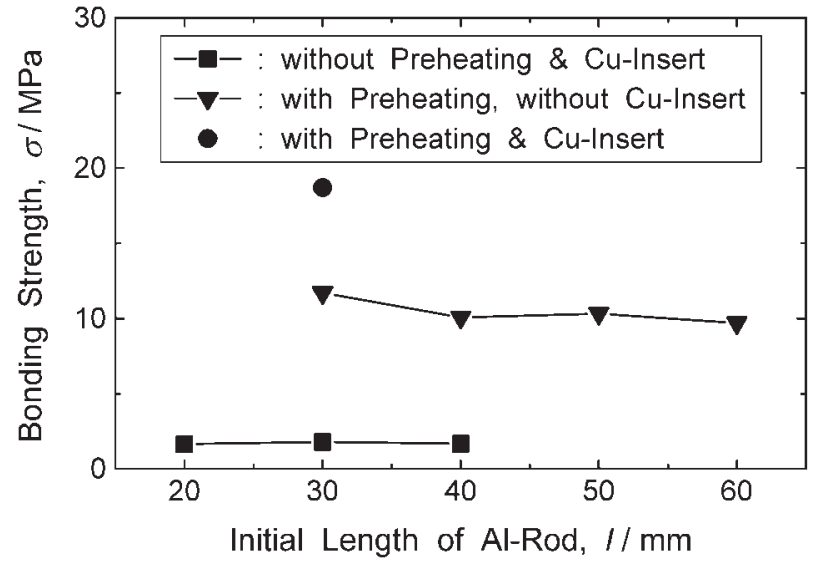

Fig. 11 Bonding strength between the $1050 \mathrm{Al}$ alloy rod and the combustion synthesized $\mathrm{Cu}-60 \mathrm{vol} \% \mathrm{TiB}_{2}$ composite.

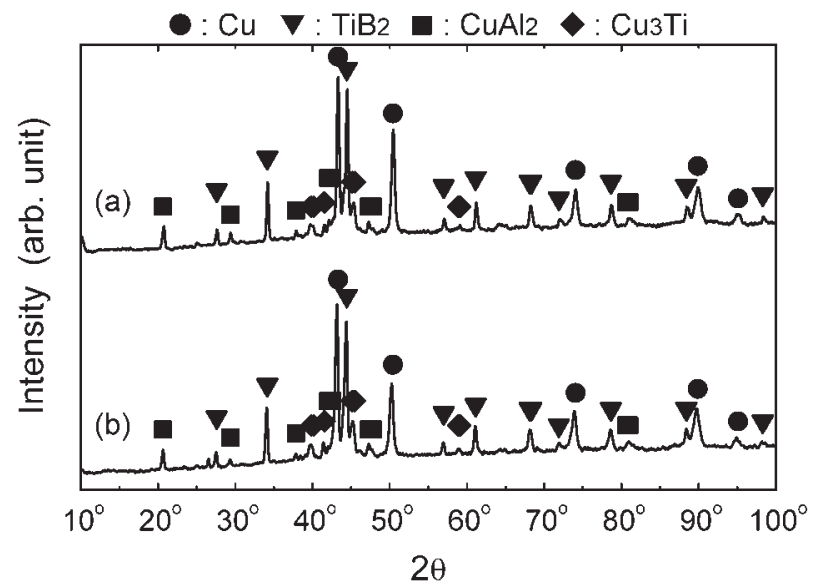

Fig. 12 XRD patterns of the fracture surfaces of the simultaneously bonded specimen between the $1050 \mathrm{Al}$ alloy rod with the length of $30 \mathrm{~mm}$ and the combustion synthesized $\mathrm{Cu}-60$ vol\% $\mathrm{TiB}_{2}$ composite without the pure $\mathrm{Cu}$ insert layer, which was ignited after preheating at $433 \mathrm{~K}$; (a) $\mathrm{Al}$ rod side and (b) composite side.

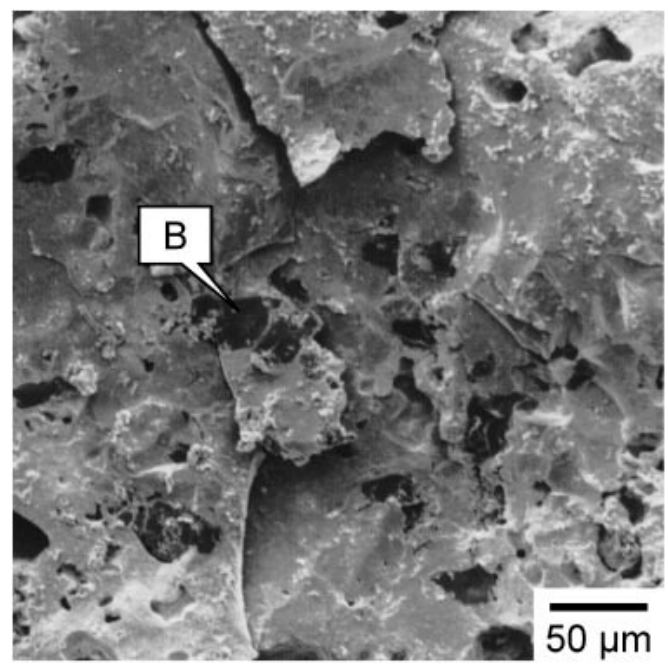

Fig. 13 SEM micrograph of the fracture surface of the simultaneously bonded specimen between the $1050 \mathrm{Al}$ alloy rod with the length of $30 \mathrm{~mm}$ and the combustion synthesized $\mathrm{Cu}-60$ vol\% $\mathrm{TiB}_{2}$ composite without the pure $\mathrm{Cu}$ insert layer, which was ignited after preheating at $433 \mathrm{~K}$. 


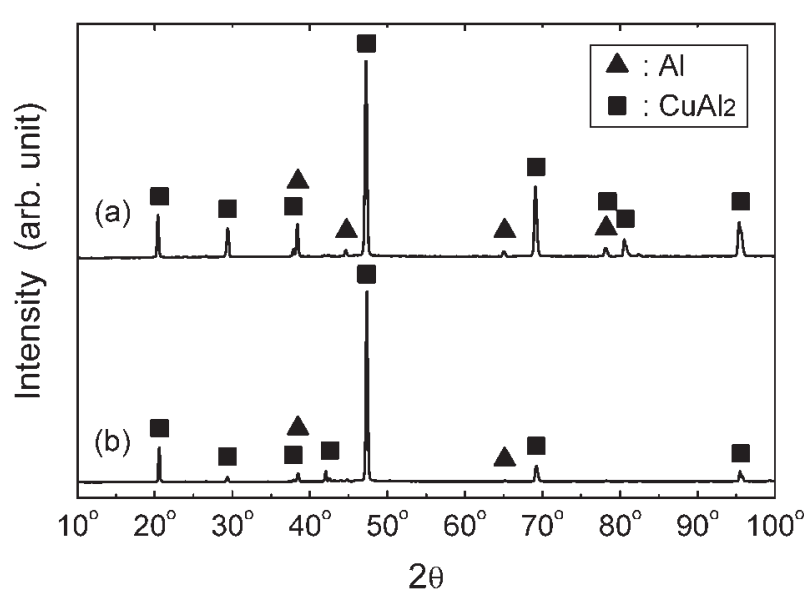

Fig. 14 XRD patterns of the fracture surfaces of the simultaneously bonded specimen between the $1050 \mathrm{Al}$ alloy rod with the length of $30 \mathrm{~mm}$ and the combustion synthesized $\mathrm{Cu}-60 \mathrm{vol} \% \mathrm{TiB}_{2}$ composite with the pure $\mathrm{Cu}$ insert layer, which was ignited after preheating at $433 \mathrm{~K}$; (a) $\mathrm{Al}$ rod side and (b) composite side.

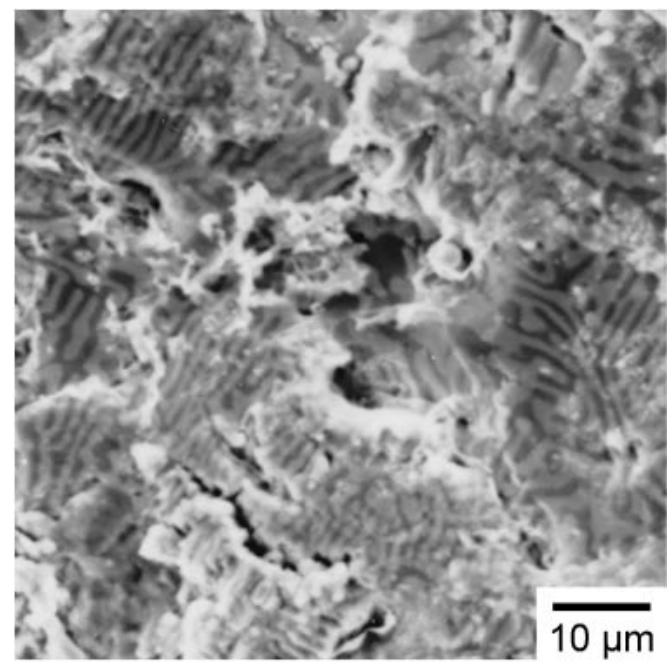

Fig. 15 SEM micrograph of the fracture surface of the simultaneously bonded specimen between the $1050 \mathrm{Al}$ alloy rod with the length of $30 \mathrm{~mm}$ and the combustion synthesized $\mathrm{Cu}-60 \mathrm{vol} \% \mathrm{TiB}_{2}$ composite with the pure $\mathrm{Cu}$ insert layer, which was ignited after preheating at $433 \mathrm{~K}$.

below $4 \mu \mathrm{m}$ in diameter were formed in situ, and homogeneously distributed in the $\mathrm{Cu}$ matrix. Also for the $\mathrm{Cu}$ 70 vol\% $\mathrm{TiB}_{2}$, the combustion reaction occurred completely without forming any unfavorable phases, although some $\mathrm{Cu}$ was evaporated during synthesizing the composite.

(2) In the Ti-B binary system, any reaction was not generated in the temperature range from room temperature to $1473 \mathrm{~K}$, indicating that the ignition temperature at which the combustion reaction between $\mathrm{Ti}$ and $\mathrm{B}$ starts is higher than $1473 \mathrm{~K}$. However, in the $\mathrm{Cu}-\mathrm{Ti}-\mathrm{B}$ ternary system, immediately after $\mathrm{Cu}$ was melted at its melting point, the combustion reaction was induced. These results suggest that the combustion reaction was activated by molten $\mathrm{Cu}$, and its ignition temperature was also decreased.

(3) The fabrication and bonding with the Al alloy of the $\mathrm{TiB}_{2} / \mathrm{Cu}$ composite were successfully carried out in a single process by using the high reaction heat generated during the combustion synthesis of the composite.

(4) Preheating before generating the combustion reaction was highly effective in bonding relatively long $\mathrm{Al}$ rods and in reducing bonding defects. Compounds consisting of $\mathrm{Al}, \mathrm{Cu}$ and $\mathrm{Ti}$ were observed with unreacted $\mathrm{B}$ in the bonded layer between the composite and $\mathrm{Al}$ alloy. For the bonded specimen with the $\mathrm{Cu}$ insert layer, the eutectic microstructure of $\mathrm{Al}$ and $\mathrm{Cu}$ was formed between the $\mathrm{Al}$ alloy and $\mathrm{Cu}$ insert, and unreacted $\mathrm{B}$ was observed with a compound of $\mathrm{Cu}$ and $\mathrm{Ti}$ between the composite and $\mathrm{Cu}$ insert.

(5) The bonding strength was enhanced by preheating before generating the combustion reaction and by inserting the $\mathrm{Cu}$ layer between the $\mathrm{Al}$ alloy and the composite.

(6) The bonded specimen with no insert layer was fractured near the bonded interface between the $\mathrm{Al}$ alloy and the composite. On the other hand, by inserting the pure $\mathrm{Cu}$ layer with preheating, the fracture occurred in the bonded layer between the $\mathrm{Al}$ alloy and the $\mathrm{Cu}$ insert.

\section{REFERENCES}

1) M. S. Nagorka, C. G. Levi, G. E. Lucas and S. D. Ridder: Mater. Sci. Eng. A 104 (1991) 277-289.

2) J. R. Groza and J. C. Gibeling: Mater. Sci. Eng. A 171 (1993) 115-125.

3) N. Zhao, Z. Liu, R. Su, Y. Cao and G. Li: J. Mater. Eng. 10 (1995) 23-25.

4) Y. V. Baikalova and O. I. Lomovsky: J. Alloy. Compd. 297 (2000) 87-91.

5) N. Sata: Ceramics Japan 24 (1989) 514-520.

6) P. Yih and D. D. L. Chung: J. Mater. Sci. 32 (1997) 1703-1709.

7) S. Yilmaz and D. C. Dunand: Compos. Sci. 64 (2004) 1895-1898.

8) Q. Xu, X. Zhang, J. Han, X. He and V. L. Kvanin: Mater. Lett. 57 (2003) 4439-4444.

9) Hyun-Ki Kang: Surf. Coat. Technol. in press.

10) S. C. Tjong and Z. Y. Ma: Mater. Sci. Eng. R 29 (2000) 49-113.

11) Z. A. Munir: Am. Ceram. Soc. bull. 67 (1988) 342-349.

12) R. D. Torres, I. E. Reimanis, J. J. Moore and G. G. W. Mustoe: Metall. Mater. Trans. B 31 (2000) 433-438.

13) S. C. Deevi and N. N. Thadhani: Metall. Mater. Trans. A 192-193 (1995) 604-611.

14) S. C. Deevi: International Journal of Refractory Metals \& Hard Materials 13 (1995) 337-342.

15) L. Chen and E. Kny: International Journal of Refractory Metals \& Hard Materials 18 (2000) 163-167.

16) J. K. Wright, R. N. Wright and G. A. Moore: Scr. Metall. Mater. 28 (1994) 501-506

17) T. Kimata, K. Uenishi, A. Ikenaga and K. F. Kobayashi: Intermetallics 11 (2003) 947-952.

18) C. Pascal, R. M. Marin-Ayral, J. C. Tédenac and C. Merlet: Mater. Sci. Eng. A 341 (2003) 144-151.

19) P. La, M. Bai, Q. Xue and W. Liu: Surf. Coat. Technol. 113 (1999) 44-51.

20) T. Kimata, K. Uenishi, A. Ikenaga and K. F. Kobayashi: Sci. Technol. Adv. Mater. 5 (2004) 251-254.

21) A. J. Swiston Jr., T. C. Hufnagel and T. P. Weihs: Scr. Mater. 48 (2003) 1575-1580.

22) S. Li, H. Duan, S. Liu, Y. Zhang, Z. Dang, Y. Zhang and C. Wu: International Journal of Refractory Metals \& Hard Materials 18 (2000) 33-37.

23) Y. J. Kwon, M. Kobashi, N. Kanetake and T. Choh: J. Japan Inst. Metals 63 (1999) 1109-1112.

24) Y. J. Kwon, M. Kobashi, N. Kanetake and T. Choh: Proc. 2nd AsianAustralasian Conf. on Composite Materials, ed. by C. S. Hong and C. G. Kim, (The Asian Australasian Association for Composite Materials and The Korean Society for Composite Materials, 2000) pp. 329-334. 
25) I. Barin, F. Sauert, E. Schultze-Rhonhof and W. S. Sheng: Thermochemical data of pure substances, 2. ed., 2. pt., (VCH, New York, 1993) p. 1528.

26) J. J. Moore and H. J. Feng: Prog. Mater. Sci. 39 (1995) 243-273.

27) Y. J. Kwon, M. Kobashi, T. Choh and N. Kanetake: J. Japan Inst. Metals 65 (2001) 273-278.

28) Y. J. Kwon, M. Kobashi, T. Choh and N. Kanetake: J. JILM 51 (2001) 351-355.

29) I. Barin, F. Sauert, E. Schultze-Rhonhof and W. S. Sheng: Thermochemical data of pure substances, 2. ed., 2. pt., (VCH, New York, 1993) pp. 110-1523.
30) M. W. Chase, Jr.: NIST-JANAF thermochemical tables, 4. ed., 2. pt, (the American Chemical Society and the American Institute of Physics for the National Institute of Standards and Technology, New York, 1998) p. 1005.

31) ASM International: Binary alloy phase diagrams, 2nd ed., version 1.0, plus updates on CD-ROM, (Materials Park, Ohio, 1996).

32) T. Enjo, K. Ikeuchi and N. Akikawa: Journal of JWS 48 (1979) 770775 .

33) M. Abbasi, A. Karimi Taheri and M. T. Salehi: J. Alloy. Compd. 319 (2001) 233-241. 